\title{
A snapshot in time: Beliefs and practices of a pre- service mathematics teacher through the lens of changing contexts and situations
}

\author{
Lyn Webb and Paul Webb \\ Nelson Mandela Metropolitan University, Port Elizabeth, South Africa \\ lyn.webb@nmmu.ac.za and paul.webb@nmmu.ac.za
}

\begin{abstract}
For the last decade research on teachers' beliefs has made a distinction between mathematics teachers' professed and attributed beliefs (practice) and studies have either found some or no correlation between the two. In this paper we investigate the beliefs and practices of a novice teacher and conclude that inconsistency between beliefs and practices may be an observer's perspective that is not necessarily shared by the teacher, and that the view that there is a possible disjuncture does not do justice to the complexity of the practitioner's tasks nor to the rapidly changing contexts and situations that may occur within a single lesson.
\end{abstract}

There has been extensive research in recent years on the relationships between the beliefs of mathematics teachers and their actual practice in the classroom (Brodie, 2001; Ensor, 1998; Ernest, 1989, 1991; Hoyles, 1992; Lerman, 1986, 2002; Pehkonen \& Törner, 2004; Thompson, 1992; Skott, 2001a, 2001b, 2004; Speer, 2005; Wilson \& Cooney, 2002). Most of these studies focus on the correlation or disparity that researchers have identified between what teachers believe they should be doing in their classrooms (their espoused beliefs or professed beliefs) and what researchers infer based on observational and other data (their practice or "attributed beliefs"). Some studies suggest a direct causality between beliefs and practices (Schoenfeld, 1992), while other do not (Hoyles, 1992).

Ernest (1991) claims that a lack of consistency results from institutional and contextual restraints and claims there is more consistency when the teacher engages in reflective practices. Thompson (1992) summarized previous studies on beliefs by claiming that teachers' beliefs about mathematics are enacted fairly consistently while Hoyles (1992) argued that there should be no expectation of a relationship between beliefs and practices and introduced the notion of situated beliefs, i.e. that situations are co-producers of beliefs and as situations change, so do beliefs. Skott (2001a) focuses on the complexities of classroom practice and maintains that consistency between beliefs and practice is a local and instantaneous phenomenon guided by critical incidents of practice.

South African teachers exhibit a variety of levels of mathematical knowledge and knowledge of pedagogy; but they all appear to have difficulty in changing their teaching practice towards methods of engaging learners in a learner-centred approach (Brodie, 2001). This difficulty suggests that it would be profitable to know more about the apparently complex relationships and interactions between teachers' beliefs and practices, as well as the effect that changing classroom contexts and activities may have on their practice.

\section{Rationale for the study}

The relationships between beliefs and practice have implications for current curriculum trends towards reform which require teachers to change their beliefs and practices in the classroom; reform that is epistemologically framed by both constructivism (von Glaserveld, 1992) and sociocultural theory (Vygotsky, 1986). Examples of such curriculum trends are, among others, engaging learners in mathematics problem solving in context and the introduction of outcomes-based curricula in South African schools; trends which have in many ways created a new role for teachers (Department of Education, 2003). Teachers are expected to develop and flexibly use a wide range 
of different tasks and approaches in order to encourage learners' active involvement in mathematical processes of experimenting, investigating, generalising and formalising, and to support their conceptual understanding and procedural competences (Skott, 2001b).

This study investigates and interrogates the relationships between the beliefs and practices of an individual in a cohort of Further Education and Training (FET) band pre-service student teachers studying at the Nelson Mandela Metropolitan University (NMMU) in Port Elizabeth, South Africa. The rationale for using a pre-service teacher was that although many beginning teachers hold the belief that mathematics is a fixed set of rules and procedures and that learning occurs through solving problems in a step-wise fashion (Phillip et al., 2007), they are generally not resistant to change and can more easily articulate their thinking in terms of the theory of what they are learning at the time than more experienced teachers who are somewhat removed from their academic experiences (Vacc \& Bright, 1999). For the purposes of this article we have highlighted the experiences of one student as she dealt with changing methods, contexts and situations during her lessons, an approach similar to that used by Skott (2001a), who also examined the beliefs and practices of one novice teacher to interrogate the roles of his school mathematics images.

\section{Categorising and classifying beliefs}

Teachers' beliefs in terms of the nature of mathematics have been expressed in the past on a continuum ranging from an absolutist viewpoint, in which mathematical truth is unquestionable, certain and objective, to a fallibilist viewpoint, in which mathematical knowledge can be seen as a social construction and is therefore fallible, i.e., it can be revised and corrected (Lerman, 1986). In turn perceptions about learning mathematics have been represented on a continuum from the mastery of skills to problem solving, while views of the teaching of mathematics have been represented by the contrasting notions of the teacher as instructor or the teacher as facilitator (Lerman, 1986).

Ernest (1989) proposed three divisions, i.e., the instrumentalist, platonist and problem-solving views of mathematics. The instrumentalist view of mathematics is that of a set of unrelated but utilitarian rules and facts, thus reducing mathematics to the accumulation of facts, rules and skills that can be used in the pursuance of some external end. The platonist view of mathematics also sees mathematics as being a static, but unified, body of certain knowledge, and implies that mathematics is something to be discovered, not created. The problem-solving view of mathematics is that of a dynamic, continually expanding field of human creation, a cultural product, which is constantly being revised and constructed.

In order to achieve methodological triangulation Pehkonen and Törner (2004) have used both qualitative and quantitative methods to investigate teachers' beliefs about mathematics and their practices within their classrooms. One technique that they have used, and which has been replicated in this study, is a method of numerical and graphical self- and observer-estimation which allows the location of teacher's beliefs and practices within three perspectives philosophically underpinned by Dionne's view of the nature of mathematics, i.e., the toolbox, system and process perspectives (Pehkonen \& Törner, 2004). The toolbox perspective views mathematics as the mastery of skills. Doing mathematics within this perspective involves calculating, using rules, following procedures and manipulating formulae. The system perspective sees mathematics as a language of logic and rigour which requires using a precise and concise language to express mathematical ideas, while the process perspective of mathematics involves a constructive process which draws from real-life experiences. Dionne's categorisations resonate strongly with Ernest's tripartite division. Because many researchers question the assumption that what is revealed in responses to a questionnaire reveals a belief system (Lerman, 2002; Wilson \& Cooney, 2002) it was decided to trial the approach propounded by Pehkonen and Törner (2004).

\section{Relationship between beliefs and practices}

While some researchers have suggested that beliefs are a major force in affecting teaching practice (Schoenfeld, 1992; Thompson, 1992), others believe that there is no direct link between beliefs and practices (Hoyles, 1992). International research shows that there is often little or no correlation between teachers' verbalization of their beliefs and their practice in the classroom (Ernest, 1989; Lerman, 1986; 2002). These findings give substance to the fact that, despite the emphasis in modern curricula on the fallabilist viewpoint (categorized by, amongst other factors, problem solving and the importance of understanding mathematics), most teachers teach mathematics as 
a body of knowledge to be memorized. These international findings are mirrored by South African studies which reveal that teachers, despite professing views of teaching within the constructivist paradigm, often use traditional approaches that lead learners to see mathematics as a subject that must be memorized and which has little utility (Webb, 2004). Ernest (1989) feels that this incompatibility may be attributed to constraints and opportunities dictated by the social context of teaching, and that these macro schoolcontext factors are likely to cause disjuncture between teachers' espoused and enacted beliefs. Thompson (1992) cites some of the social context issues that complicate the relationship between beliefs and practices as, amongst others, the expectations held by learners, parents and colleagues, and issues of authority and control.

Hoyles (1992) adds that inconsistencies between beliefs and practices are accentuated when teachers are faced with an innovation, such as the contextual, problem solving approach to teaching mathematics propagated by the most recent South African National Curriculum Statement (Department of Education, 2003). She advocates that the mismatches between beliefs and practices often stem from situations, context and culture, which are the co-producers of what she calls "situated beliefs". It is the situational, contextual and cultural nature of her situated beliefs and practices that lead her to the feeling that mismatches between beliefs expressed outside the classroom, and practices demonstrated inside the classroom, should be expected. Ensor (1998) supports this view, noting that beliefs are not stable across contexts, and that differences in social situations result in multiple positioning of teachers, suggesting that beliefs are fore-grounded and backgrounded according to the context in which the person is operating at the time. This notion is supported by Pehkonen and Törner's (2004) statements that beliefs are temporal and subject to continuous evaluation and change, a view echoed by Lerman (2002) who maintains that changes in beliefs affect practice, and that, in turn, changes in practice affect the beliefs of the practitioner.

Research by Skott (2001a) on mathematics teachers' beliefs provides data which suggests that there can be simultaneous existence of multiple, and possibly conflicting, communities of practice in the course of classroom interaction. Skott (2001a) maintains that interactions with students can transform beliefs and therefore it is inappropriate to describe teachers' beliefs and practices as being inconsistent as it minimises the complexity of the teaching task. He sees communities of practice developing where the contributions of both individuals and groups become accepted in the class and become part of the mathematical discourse. Within this view the role of the teacher is to sustain these individual and collective learning opportunities by adjusting his or her teaching style to each situation as it occurs. Skott (2001b) maintains that micro aspects, such as classroom atmosphere and interactions between the teacher and specific groups of learners, are essential to the understanding of the social context and thus the teacher's practices. He does not focus on the congruence or conflict between beliefs and practices, but attempts to disentangle the ways in which the multiple communities interact and frame the emergence of different strategies in teaching practice.

\section{Method}

As suggested above, there are a number of ways of looking at beliefs on the nature of mathematics, as well as of locating teachers' beliefs and practices in terms of this area of knowledge. What is clear though is that during the past decade, many researchers have concentrated on research conducted mostly within a cognitive framework and considered the implications of teachers' beliefs from this perspective (Speer, 2005). In contrast Skott (2001a) has developed a construct of "critical incidents of practice" and Barwell (2005) has concentrated on the socio-cultural contexts in which teaching and learning practices are coconstructed by participants (Speer, 2005).

In this paper we frame the findings generated by our study within Lerman's (1986), Dionne's (1984, as cited in Pehkonen \& Törner, 2004) and Ernest's (1989) views of the nature of mathematics and Pehkonen and Törner's (2004) technique of locating teacher's beliefs and practices within philosophical perspectives of the nature of mathematics. In turn we use Skott's (2001a) understandings of how micro aspects of the social context of mathematics education (such as classroom climate, the teacher's motives or the interactions between the teacher and specific learners) impinge on practices as backings and warrants for the arguments we use in terms of importance (or non-importance) of disjunctures between teachers' beliefs and practices.

Our student, as part of a group of pre-service mathematics teachers, was given Zollman and 
Mason's 1992 Standards Belief Instrument (Furner, 2004, p. 56) in order to gauge her professed attitudes towards reform in teaching (Appendix A). She was also given a questionnaire developed and tested by Pehkonen and Törner (2004) on conceptions of teaching mathematics (Appendix B). Because research has shown that respondents have not always responded consistently to questionnaires (Wilson \& Cooney, 2002) these two questionnaires were used to get an indication as to whether her answers were consistent.

Speer (2005) warns that the discrepancy between what teachers say they believe and what is reflected in their practice may be caused by the very methods used to collect the data, or caused by a lack of shared understanding between the teachers and researchers of the terms used to describe both beliefs and practices. Thus, a more visual, graphic approach was implemented where the participating pre-service student filled in a table developed by Pehkonen and Törner (2004) based on Dionne's perspectives concerning Toolbox, System and Process views of mathematics. She was also asked to distribute a total of 30 points corresponding to her estimation of her "real" teaching of mathematics and her "ideal" teaching of mathematics. The research was undertaken at the end of the student's teaching practice so she had been teaching in classrooms for more than six months. Furthermore, the student was also asked to mark a point on an equilateral triangle with " $X$ " to indicate her "real" teaching of mathematics and to indicate her "ideal" teaching of mathematics with an "O" (Appendix C). The vertices of the triangle represented the Toolbox, Process and System perspectives on mathematics as propounded by Dionne (1984, as cited in Pehkonen \& Törner, 2004). The student was then interviewed about her beliefs of the nature of mathematics and her views of teaching and learning mathematics in order to interrogate her responses more carefully and to ensure that she had a shared understanding of the terms used to describe beliefs and practices.

As noted earlier, the student showcased in this study was one of a group of pre-service mathematics teachers who were given an opportunity to showcase their teaching practice during a videotaped lesson in the classroom. After the recorded lessons these students were reinterviewed and selected excerpts from these videotapes were used to allow them to explain the reasoning behind their actions and to enable the researcher to probe beliefs tied to specific examples of the students' practices, as well as to attribute beliefs more accurately (Speer, 2005).

The data generated by the research suggested similar beliefs and teaching styles for four out of five students in the group (which can possibly be attributed to the fact that they had all been recently influenced by the input of their Post Graduate Certificate in Education (PGCE) Mathematics Method lecturer). For the purposes of this paper we focused on our selected student, Sarah, as although her beliefs showed the highest correlation in both of the questionnaires and her graphical and numerical self assessment tasks mapping her "real" and "ideal" teaching reflected the same trends in beliefs as her questionnaire responses, her professed beliefs and her classroom practice were consistent at times, but clearly disparate at others (more noticeably than the other students). This highlighting of a relatively clear-cut case is similar to the research done by Skott (2001a), where he also examined the beliefs and practices of one novice teacher.

\section{Results}

The scores achieved in Zollman and Masons' (1992) Standards Belief Questionnaire (Furner, 2004) on a scale of $1=$ strongly disagree, $2=$ disagree, $3=$ agree, $4=$ strongly agree, were totalled and Sarah scored 46, despite leaving out three questions relating to kindergarten and intermediate phase mathematics, which were not relevant to her as a grade 10-12 teacher. This score suggests that Sarah has a tendency towards reform beliefs in teaching, encompassing beliefs that mathematics should be a meaningful, problem solving activity where active learning and solid reasoning are encouraged.

During an initial interview before the teaching practice, Sarah re-iterated her commitment to teaching reform i.e., that she believed in a learnercentred teaching and constructivist learning approach. However, she made some contradictory statements, for example:

Developing the skill of critical analysis and problem solving through mathematics is very valuable in all facets of life... Free thinking is so important.

was contrasted with:

I think that through repetition and practice certain things become automatic without parrot-style memorization. 
This statement suggests that, although Sarah subscribes to a problem solving philosophy (Process perspective), she sees repetition and mastery of skills as important in mathematics (Toolbox perspective); however, she has qualified her statement which indicates that she has reflected about her stance.

Sarah's response to the Pehkonen and Törner (2004) questionnaire also suggested that she has an innovative, learner-centred approach to mathematics teaching. Although she was indecisive about the role of proofs and the role of visualization in teaching mathematics; she was positive about using varied application exercises, problem solving, developing thinking skills and stressing understanding. Sarah's scores were consistent when using both questionnaires (the Standard Beliefs and Pehkonen and Törner's questionnaire) and they suggested a constructivist view of mathematics learning and reform teaching in both instruments.

It is interesting to note that in the initial interview she was ambivalent about the role of understanding. When asked whether she felt it was more important to teach skills or emphasise learners' understanding when teaching, she answered:

Neither. I know this is the easy way out, but it is true. I believe both are equally important and are used together most of the time.

In the self-evaluation table Sarah misread the instructions and distributed 20 points instead of 30 between the Toolbox, System and Process perspectives of real and ideal teaching. She gauged her "real" teaching of mathematics to be mainly Toolbox (9) > System (7) > Process (4). She viewed the "ideal" teaching of mathematics to be Toolbox (8) = Process (8) > System (4). This correlated with the ideas expressed in the interview that both skills and understanding are of equal importance. The exercise also showed that she did not feel that her "real" teaching style encouraged a constructive process.

In the visual representation of her "real" teaching style, as opposed to "ideal" teaching style, Sarah positioned her "real" teaching style (represented by $\mathrm{X}$ ) midway between Toolbox and System, far away from a process approach, as is shown in Figure 1. Her view of an "ideal" teaching style (represented by $\mathrm{O}$ ) tended towards process, but remained midway between Process and Toolbox. This graphically mirrored her results in the selfevaluation table. An advantage of the graphic method is that one can draw a vector from the "real" to the "ideal" view to indicate how far from the "ideal" the teacher views his or her "real" teaching to fall. In this case Sarah showed that she felt a balance between the three perspectives, leaning away from a system approach, was an ideal perspective.

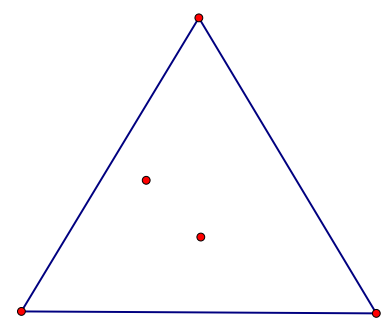

Figure 1: Sarah's graphical representation of her "real" $(X)$ teaching style and her "ideal" $(O)$ teaching style

On reviewing the videotape of her lesson in the classroom, two contrasting incidents occurred where she enacted reform-based teaching methods and diametrically opposed traditional teachercentred teaching methods.

In the first instance Sarah was showing the whole class how to find the area of a circle if given the radius. She stated the formula and wrote it on the board. She emphasized to the whole class that:

All these examples are exactly the same. Even if you do know, that's fine, we'll go over it all again. There's only one method to do all of these because they're all the same, just different numbers so if you get the method right you can do all of them - $a, b, c, d$.

Sarah proceeded to go through a few examples finding the area of a circle before giving them more of the same exercises to complete. She also emphasized that the answers should all be expressed in square metres:

...because if you don't you'll be wrong and you'll lose marks.

In this incident Sarah demonstrates a Toolbox perspective of mathematics where mastery of skills and applying rules is emphasised.

In the second incident, Sarah arranged the class in pairs and emphasized that this was a co-operative 
learning technique where discussion in pairs around solving the problem was essential. She gave them a problem and said:

I am trying to get you to use all the things you have learned in the last two weeks in one sum.

She emphasised the process rather than the product by stating:

I want you to hand it in so we can see where you are going wrong.

The problem involved a castle on a piece of circular land with a moat around it. Sarah introduced a contextual element by discussing with the class the reason for a moat:

In the olden days they had castles and they used to keep the baddies out with a moat. What happened when their friends came? They just put a drawbridge over it.ty

The problem involved finding the area of the rectangular castle, the area of the circular land and the area of the moat. Although the problem was a thinly disguised skills-based exercise, Sarah stated in the interview after the lesson that she believed that she had contextualised the problem and she believed that she had engaged the learners in cooperative problem solving. This indicates that despite studying a mathematics method course, she has a superficial understanding of the nature of mathematical problem solving.

In the course of a single lesson Sarah had used two opposite styles of teaching with the same learners. She had expected them to learn through a repetitious approach and a collaborative approach where the learners communicated in pairs in order to solve a contextual problem. In the interview afterwards she saw no disjuncture between the two perspectives. Sarah explained that in the toolbox section of her lesson she was preparing the learners for the forthcoming test that would be skills-based and in the process section she was endeavouring to introduce an element of contextual problem solving using collaborative learning. She thus divides the lesson into a conceptual section, where she believes a problem solving approach can aid cognition, and a procedural section, where traditional rote learning is her preference.

\section{Conclusion and implications}

Skott (2001b) claims that the motives for a teacher's activities emerge in the course of classroom interactions and that previously espoused beliefs may become less significant, depending on the particular context at the time.

It is apparent that Sarah's professed perspectives on mathematics were relatively constant, whether she completed a questionnaire or self-evaluation task or expressed an opinion during an interview, as she consistently expressed reform-based views. She mentioned investigations and experimentation as ideal ways of enhancing learner understanding; she claimed that learning mathematics included ways of approaching and posing problems; and she saw her role in teaching as a guide and facilitator of learning. However, her classroom practices reflected both a Toolbox approach and a Process approach - in Lerman's (1986) terms she demonstrated an absolutist viewpoint and a fallibilist viewpoint - at different occasions during the same lesson. She emphasised mastery of skills at one stage and a problem solving approach at another stage of the lesson. She acted as both instructor and facilitator. She demonstrated both a traditional "chalk-and-talk" style as well as a more innovative contextual, problem solving approach. Her classroom practices, therefore, seemed at times to be consistent and at times to be inconsistent with her verbalised beliefs - depending on how her beliefs were situated in a particular context.

Sarah's explanation that, firstly, she was carrying out instructions from the senior teacher to drill the learners for an upcoming skills test shed light on an external factor that dictated practice, as opposed to a disjuncture between her espoused beliefs and enacted practice. Secondly, she endeavoured to implement a problem solving aspect into the lesson because of her innate belief in constructivist learning. Her explanations validate Speer's (2005) advice that instead of focusing extensively on the differences between professed and attributed beliefs, researchers should instead focus on the explanations generated by the teachers for the reasons for their instructional decisions during specific instances of interactions with learners in the classroom. Thus, it may be possible to refine existing theories concerning the link between beliefs and practices in order to understand the phenomenon better.

Sarah explained that although she had planned her lesson meticulously, there were many occasions where she had to "think on her feet" and had to deviate from the predetermined teaching practice. This echoes Skott's (2001b) standpoint that the motives behind teachers' practices are not fixed by 
previously stated beliefs, but by entities that may be transformed as a result of interactions with learners and a multiplicity of different tasks that emerge during a lesson.

It is not possible, from this study, to predict whether Sarah will hold her professed beliefs over time or whether her beliefs and practices are cyclical and open to change as she develops into a more experienced teacher (Lerman, 2002). What is apparent, though, is that a teacher's activity is likely to be related to the sense s/he makes of the classroom situation which will draw the focus of a certain activity at a specific moment onto a particular aim. This means that inconsistency between beliefs and practices may be an observer's perspective that is not necessarily shared by the teacher, and that the view that there is a disjuncture may not do justice to the complexity of the teacher's tasks (Skott, 2004).

We agree that the context and complexity of classroom interactions have become increasingly more demanding on novice teachers, and that this understanding has implications when trying to change, measure and understand teachers' beliefs and practice during periods of curriculum reform, such as is currently demanded by the National Curriculum Statement for Mathematics (Department of Education, 2003). University teacher training courses aim at inculcating sustainable constructivist beliefs about teaching and learning, but the question is what is being done to assist novice teachers to recognise and deal with the rapidly changing contexts and situations that may occur within a single lesson and which may challenge these beliefs - as well as help them understand that what some may see as a disjuncture may simply be a product of the complexity of the practitioner's tasks?

\section{References}

Barwell, R. (2005). Ambiguity in the mathematics classroom. Language and Education, 19(2), 118126.

Brodie, K. (2001). Changing practices, changing knowledge: towards mathematics pedagogical content knowledge in South Africa. Pythagoras, 54, 17-25.

Department of Education. (2003). National Curriculum Statement: Grades 10-12 (General). Mathematics. Pretoria: Department of Education.

Ensor, P. (1998). Teachers' beliefs and the 'problem' of the social. Pythagoras, 46/47, 3-7.
Ernest, P. (1989). The impact of beliefs on the teaching of mathematics. In Mathematics Teaching: The State of the Art. London: Falmer Press.

Ernest, P. (1991). The philosophy of mathematics education. London: Falmer Press.

Furner, J. (2004). Implementing the National Council of Teachers of Mathematics Standards: A slow process. Pythagoras, 59, 46-56.

Hoyles, C. (1992). Illuminations and reflections Teachers, Methodologies and Mathematics. In W. Geeslin \& K. Graham (Eds.), Proceedings of the Sixteenth International Conference for the Psychology of Mathematics Education, 3, 263286. Durham, New Hampshire, USA.

Lerman, S. (1986). Alternative views of the nature of mathematics and their possible influence on the teaching of mathematics. Unpublished doctoral dissertation, University of London, UK.

Lerman, S. (2002). Situating research on mathematics teachers' beliefs and on change. In G. Leder, E. Pehkonen \& G. Törner (Eds.), Beliefs: A hidden variable in mathematics education? (pp. 233243). Dordrecht: Kluwer.

Pehkonen, E., \& Törner, G. (2004). Methodological considerations on investigating teachers' beliefs of mathematics and its teaching, Nordisk Matematikk Didadtikk, 9(1), 21-49.

Philipp, R., Ambrose, R., Lamb, L., Sowder, J., Schappelle, P., Sowder, L., Thanheiser, E. \& Chauvot, J. (2007). Effects of early field experiences on the mathematical content knowledge and beliefs of prospective elementary school teachers: An experimental study. Journal for Research in Mathematics Education, 38(5), 438-475.

Schoenfeld, A. H. (1992). Learning to think mathematically: Problem solving, metacognition, and sense making in mathematics. In D. Grouws (Ed.), Handbook of research on mathematics teaching and learning. New York: Macmillan.

Skott, J. (2001a). The emerging practices of a novice teacher: The roles of his school mathematics images. Journal of Mathematics Teacher Education, 4(1), 3-28.

Skott, J. (2001b). Why belief research raises the right question but provides the wrong type of answer. Proceedings of the 3rd Nordic Conference on Mathematics Education. Högskolan Kristianstad.

Skott, J. (2004). The forced autonomy of mathematics teachers. Educational Studies in Mathematics, 55(1-3), 227-257.

Speer, N. (2005). Issues of method and theory in the study of mathematics teachers' professed and attributed beliefs. Educational Studies in Mathematics, 58(3), 361-391. 
Thompson, A.G. (1992). Teachers' beliefs and conceptions: A synthesis of the research. In D. A. Grouws (Ed.), Handbook of research on mathematics teaching and learning (pp. 127-146). New York: Macmillan.

Von Glaserveld, E. (1992). A constructivist's view of learning and teaching. In R. Duit, F. Goldberg \& H. Niedderer (Eds.). Research in physics learning: Theoretical issues and empirical studies. Kiel: Institute for Science Education.

Vacc, N., \& Bright, G. (1999). Elementary preservice teachers' changing beliefs and instructional use of children's mathematical thinking. Journal of Research in Mathematics Education, 30, 89-110.
Vygotsky, L. S. (1986). Thought and language. Cambridge, Massachusetts \& London: The MIT Press.

Webb, L. (2004). Teachers' understanding of the nature of mathematics. Unpublished MEd thesis, Nelson Mandela Metropolitan University, South Africa.

Wilson, M., \& Cooney, T. (2002). Mathematics teacher change and development. The role of beliefs. In G. Leder, E. Pehkonen, \& G. Törner (Eds.), Beliefs: A hidden Variable in mathematics education? (pp. 127-148). Dordrecht: Kluwer. 


\section{APPENDIX A: STANDARDS’ BELIEF INSTRUMENT}

Directions: Shade in the answers that best describe your feeling about the following statements on the scantron grid provided. Use the following code:

$1=$ strongly disagree $\quad 2=$ disagree

3 = agree 4 = strongly agree

\begin{tabular}{|c|c|c|c|c|c|}
\hline 1 & $\begin{array}{l}\text { Problem solving should be a SEPARATE, DISTINCT part } \\
\text { of the mathematics curriculum. }\end{array}$ & 1 & 2 & 3 & 4 \\
\hline 2 & $\begin{array}{l}\text { Students should share their problem-solving thinking and } \\
\text { approaches WITH OTHER STUDENTS }\end{array}$ & 1 & 2 & 3 & 4 \\
\hline 3 & $\begin{array}{l}\text { Mathematics can be thought of as a language that must be } \\
\text { MEANINGFUL if students are to communicate and apply } \\
\text { mathematics productively. }\end{array}$ & 1 & 2 & 3 & 4 \\
\hline 4 & $\begin{array}{l}\text { A major goal of mathematics instruction is to help children } \\
\text { develop the beliefs that THEY HAVE THE POWER to } \\
\text { control their own success in mathematics. }\end{array}$ & 1 & 2 & 3 & 4 \\
\hline 5 & $\begin{array}{l}\text { Children should be encouraged to justify their solutions, } \\
\text { thinking, and conjectures in a SINGLE way. }\end{array}$ & 1 & 2 & 3 & 4 \\
\hline 6 & $\begin{array}{l}\text { The study of mathematics should include opportunities of } \\
\text { using mathematics in OTHER CURRICULUM AREAS. }\end{array}$ & 1 & 2 & 3 & 4 \\
\hline 7 & $\begin{array}{l}\text { The mathematics curriculum consists of several discrete } \\
\text { strains such as computation, geometry, and measurement } \\
\text { which can be best taught in ISOLATION. }\end{array}$ & 1 & 2 & 3 & 4 \\
\hline 8 & $\begin{array}{l}\text { Learning mathematics is a process in which students } \\
\text { ABSORB INFORMATION, storing it in easily retrievable } \\
\text { fragments as a result of repeated practice and reinforcement. }\end{array}$ & 1 & 2 & 3 & 4 \\
\hline 9 & $\begin{array}{l}\text { Mathematics SHOULD be thought of as a COLLECTION of } \\
\text { concepts, skills and algorithms. }\end{array}$ & 1 & 2 & 3 & 4 \\
\hline 10 & $\begin{array}{l}\text { A demonstration of good reasoning should be regarded EVEN } \\
\text { MORE THAN students' ability to find correct answers. }\end{array}$ & 1 & 2 & 3 & 4 \\
\hline 11 & $\begin{array}{l}\text { Appropriate calculators should be available to ALL } \\
\text { STUDENTS at ALL TIMES. }\end{array}$ & 1 & 2 & 3 & 4 \\
\hline 12 & Learning mathematics must be an ACTIVE PROCESS. & 1 & 2 & 3 & 4 \\
\hline
\end{tabular}

Source: Zollman \& Mason, 1992, as cited in Furner, 2004, p. 56. 


\section{APPENDiX B: A QUESTIONNAIRE FOR TEACHERS CONCEPTION OF TEACHING MATHEMATICS}

Through the following questionnaire, we would like to get a profile of your ideas and conceptions concerning teaching mathematics. These are some statements on teaching mathematics. Circle the option which best describes your opinion.

\begin{tabular}{|c|c|c|c|c|c|c|}
\hline \multicolumn{4}{|c|}{ 1=fully agree } & \multicolumn{2}{|c|}{$2=$ agre } & $5=$ fully disagree \\
\hline 1 & 1 & 2 & 3 & 4 & 5 & $\begin{array}{l}\text { In teaching mathematics, one should use varied exercises and applications } \\
\text { above all else. }\end{array}$ \\
\hline 2 & 1 & 2 & 3 & 4 & 5 & $\begin{array}{l}\text { Mathematics in school necessarily requires a concrete dimension; abstract } \\
\text { mathematics alone is not enough. }\end{array}$ \\
\hline 3 & 1 & 2 & 3 & 4 & 5 & $\begin{array}{l}\text { Logic is promoted in teaching mathematics, whereas creativity and originality } \\
\text { are not stressed. }\end{array}$ \\
\hline 4 & 1 & 2 & 3 & 4 & 5 & Problem orientation should be the core of teaching mathematics. \\
\hline 5 & 1 & 2 & 3 & 4 & 5 & $\begin{array}{l}\text { In teaching mathematics, finished products take priority, not the process by } \\
\text { which they are achieved. }\end{array}$ \\
\hline 6 & 1 & 2 & 3 & 4 & 5 & Doing mathematics means: working through the proofs carefully. \\
\hline 7 & 1 & 2 & 3 & 4 & 5 & $\begin{array}{l}\text { Teaching mathematics provides an excellent opportunity to promote the } \\
\text { development of the pupils' thinking. }\end{array}$ \\
\hline 8 & 1 & 2 & 3 & 4 & 5 & Mathematics teaching is especially meant for talented pupils. \\
\hline 9 & 1 & 2 & 3 & 4 & 5 & One should always make sure to visualize aspects of teaching mathematics. \\
\hline 10 & 1 & 2 & 3 & 4 & 5 & Indisputable formality takes priority in mathematics. \\
\hline 11 & 1 & 2 & 3 & 4 & 5 & Learning calculation techniques is the core of teaching mathematics. \\
\hline 12 & 1 & 2 & 3 & 4 & 5 & While doing mathematics, understanding the topic is the most important idea. \\
\hline 13 & 1 & 2 & 3 & 4 & 5 & $\begin{array}{l}\text { In teaching mathematics, one should often realize projects without subject } \\
\text { limits. }\end{array}$ \\
\hline
\end{tabular}

Source: Pehkonen \& Törner, 2004, p. 45. 


\section{APPENDIX C: NUMERICAL AND GRAPHICAL SELF EVALUATION}

Starting point: A rough classification of mathematical views consists of the following three perspectives, which are part of every view of mathematics and the teaching of mathematics:

T Mathematics is a large toolbox: Doing mathematics means working with figures, applying rules and procedures and using formulas.

S Mathematics is a formal, rigorous system: Doing mathematics means providing evidence, arguing with clear and concise language and working to reach universal concepts.

P Mathematics is a constructive process: Doing mathematics means learning to think, deriving formulas, applying reality to Mathematics and working with concrete problems.

Question 1: Distribute a total of 30 points corresponding to your estimation of factors, $\mathrm{T}, \mathrm{S}$, and $\mathrm{P}$ in which you value your...

\begin{tabular}{|l|l|l|l|}
\hline & T & S & P \\
\hline ... real teaching of mathematics & & & \\
\hline ... ideal teaching of mathematics & & & \\
\hline
\end{tabular}

For additional comments please use the reverse side of this page.

Question 2: Acknowledge your position on the three factors mentioned above by marking points within the equilateral triangle below.

$$
\begin{aligned}
& \mathrm{X}=\text { real teaching of mathematics } \\
& \mathrm{O}=\text { ideal teaching of mathematics }
\end{aligned}
$$

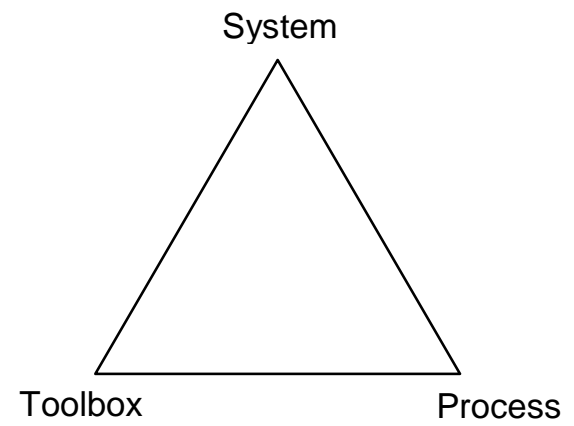

For additional comments please use the reverse side of this page. Thank you very much!

Source: Pehkonen \& Törner, 2004, p. 46. 